\title{
Harmful Traditional Practices Against Women and Children in Yem Special Woreda, SNNPR, Ethiopia
}

\author{
Aschale Kassie ${ }^{1^{*}} \quad$ Temesgen Melaku ${ }^{2}$ \\ 1.College of Social Sciences and Humanities, Wolkite University, PO box 07, Ethiopia \\ 2.College of Education and Behavioural Sciences, Wolkite University, PO box 07, Ethiopia
}

\begin{abstract}
This study was conducted to assess the overall status of harmful traditional practices against women and children in Yem special woreda, SNNPR, Ethiopia. It involved the use of cross-sectional research design with the purpose of exploring the issue in focus. Methods of data collection such as key-informant interview (KII), FGD and structured interview were used to gather data required to meet to objectives of the study. The data and discussions showed that HTPs that affect children, particularly 'feeding butter to babies' are found to be more prevalent as compared to other forms. This practice could have a number of health related impacts on babies. HTPs such as child/early marriage are nowadays becoming less prevalent as compared to the past times based our data and discussions implications. In the study, it was found that, FGM-a type of harmful practice that significantly affects girls/women in other parts of Ethiopia, is not a serious problem in the study area. Social interaction and cultural contacts with neighboring cultural communities may still leave a gap where FGM/C get chance to spread to parts of the study area though. Marriage by abduction is not common in the study area based on our systematic investigation. Still occasional acts of rape and other forms of violence against school girls are being witnessed. Polygamous marital arrangements are to some extent prevailing in the study area, especially, in more remote rural kebeles.
\end{abstract}

Keywords: Harmful traditional practices, Yem special woreda, child marriage, women and children

DOI: $10.7176 /$ RHSS/10-15-03

Publication date:August $31^{\text {st }} 2020$

\section{Introduction}

National Strategy on Harmful traditional Practices (HTPs) against women and children in Ethiopia, prepared by the Ministry of Women, Children and Youth Affairs in collaboration with development partners and endorsed in 2013, defined HTPs as 'traditional practices which violate and negatively affect the physical, sexual, psychological well-being, human rights and socio-economic participation of women and children'. Harmful Traditional Practices are a form of discrimination; they violate the human rights of affected individuals, particularly women and girls. They arise from gender inequality and discriminatory values, which lead to unequal power relations in communities and societies and to violence against women and girls ( $\mathrm{ibid}$ ).

FGM, an ancient ritual, is believed to be practiced by 28 African countries particularly sub-Saharan and Northeastern African communities. While no definitive statistics are available with regard to the prevalence of female genital mutilation, it is estimated that 100 million women and 140 million girls have undergone FGM worldwide. Despite global efforts to promote elimination of the practice, it remains widespread in Africa and an approximate 2 million girls are at risk of undergoing the practice of FGM in Africa annually (Makundi, 2009). Female genital cutting denotes all procedures involving partial or total removal of the external female genitalia, or other injury to the female genital organs for non-medical reasons, and 'early marriage' is defined as any union between individuals under the age of 18 years, this being the upper limit of childhood internationally and the minimum legal age of marriage in Ethiopia (Boyden et al, 2012).

HTPs in Ethiopia include: Female Genital Mutilation/Cutting (FGM/C), child marriage, Son preference, bride-price, Polygamy, widow inheritance, Excessive feasting, dowry payments and Honor-killings, Massaging the abdomen of pregnant woman with butter during difficult labor Marriage by abduction, Shaking women violently to cause placental delivery, Throat piercing using hot iron rods, Giving "Kosso" to pregnant women, Encouraging excessive fertility, plucking finger nails of women prior to weddings, Application of cow dung etc. to the umbilical cord, Milk teeth extraction, Food taboos, Forbidding food and fluids during diarrhea, Keeping babies out of the sun, Hiding children with disability, Feeding fresh butter to new born babies, Eyelid incision, Tribal marks, Cauterization, Bloodletting, Tattooing, Emasculation and others (Assefa, et al, 2005).

Despite the concerns given to HTPs by different agents including the government, researchers, NGOs and other bodies in Ethiopia, harmful traditional practices are still prevalent having different forms. Though no reliable and up to date data on the prevalence of different Harmful Traditional Practices (HTPs) in Ethiopia, the available evidence indicates that Female Genital Mutilation/ Cutting (FGM/C), abduction for marriage and early forced and child marriage constitute the most prevalent forms of violence against women/girls that adversely affect millions of women and girls in the country (UNICEF-Ethiopia, 2015).The SNNPR has made relatively better achievement compared to other regions in reducing child marriage. 41 per cent and 16 per cent of women 
aged 20-24 got married before the age of 18 and 15 respectively. The regional variation holds true for the child marriage as well; the highest prevalence rate is in Amhara (44.8 per cent), followed by Tigray (34.1 per cent), Benishangul-Gumuz (31.9 per cent) and Addis Ababa at 32.3 per cent. From the 1997 baseline survey up to the follow up survey of 2008, the highest decline is observed in SNNP regional state where the prevalence rate declined from 18.7 per cent to 9.9 per cent and in Benishangul-Gumuz where it declined from 50.1 per cent to 31.9 per cent (ibid).

\section{Objectives and Scope of the Study}

The general objective of this study is to assess the overall status of harmful traditional practices (with special emphasis on women and children) in Yem liyu woreda, SNNPR. Based on the above general objective, the study was carried with the purpose of meeting the following specific objectives. These are:

$\checkmark$ Identifying the major types of harmful traditional practices that prevail in the study area,

$\checkmark \quad$ Identify and recommend possible and appropriate mechanisms of intervention to reduce and avoid alltogether HTPs and their negative impacts on the life of people (taking women and children at the center of focus) in the study area.

The scope of this assessment is limited to examining the overall status of HTPs against women and children in Yem Special Woreda. More precisely, HTPs such as child/early marriage, FGM, polygamy, marriage by abduction and others harmful practices that impact women and children were emphasized. It was also attempted to review the efforts that are made in line with tackling these practices. The gaps left and possible way outs to this was also another point of focus in this assessment.

\section{Methods and Materials}

Study Area: The Yem people are living in Yem special woreda which is located within the Southern Nations, Nationalities and Peoples (SNNP) Regional State according to the federal administrative structure of the present Ethiopian government. Based on the 2007 Census conducted by the Central Statistical Agency of Ethiopia (CSA), this woreda has a total population of 80,687. The neighbors of the Yem are the Gurage, Hadiya, and Kambata to the east across the Gibe River and Jimma zone to the south, north, and west. The area is situated at an altitude ranging between 500 and 3,500 meters and between 7030' $\mathrm{N}$ and 8035' $\mathrm{N}$ latitude and $41025^{\prime} \mathrm{E}$ and 41 055' E longitude (Getachew, 2001 cited in Lemma et al., 2019). The region covers only about 34,000 hectares of land, mainly comprising mountain ranges, gorges, and deep valleys (Tiffin, 1965 cited in Getachew, 2001). The Yem are one of the indigenous people of south-west Ethiopia who used to have their own kingdom, with an elaborate system of political and administrative structure (Aklilu, 2002 cited in Lemma et al., 2019).

The native language of Yem people is Yemsa, which is one of the Omotic languages. Althogh many Yem people speak Amharic and Affan Oromo, some also speak Gurage and Hadiya Languages. Yemsa (Yem lamguage) has also close relationship to the Wawro, Kafficho, Wolaita, Bench and Sheko languages. Yemsa is one of the endangered languages, however with the current introduction of self administration, and subsequent measures or efforts to promote ans sustain the language, it is gaining the momentum of its growth (Milkyas, 2017: 8).

The recent capital of the special woreda is Saja located at 239 KMs away from Addis Ababa and 527 KMs from Hawassa. The Yem exercise distinctive circumcision of young male and hosting menstruation period for the female as a symbol of transition to physical maturity (Milkyas, 2017: 8).

Research Design/Approach: This study involved the use of cross-sectional research design with the purpose of exploring the issue in focus. Methods of data collection such as key-informant interview (KII), FGD and structured interview were used to gather data required to meet to objectives of the study. The study basically emphasized qualitative approaches for data collection, interpretation and analysis.

Sources of Data: In this study, both primary and secondary sources of data have been used. We have tried to consult various types of documents, literature and government reports as secondary sources of data. In addition, FGDs, KIIs and structured interview were used to gather primary data.

Instruments of Data Collection: Three FGDs were conducted, in which issues related to the common types of HTPs in the area, severity of the problems, local justifications for the practices, HTPs tackling efforts and related issues were discussed in a detailed manner. The focused groups were comprised of mothers, young community members, religious leaders and local administrators. In-depth interviews/discussions were undertaken with Yem Special Woreda Women and Children Affairs Department Deputy Head, one law expert in the department, police officer, health extension workers, Yem Special Woreda Health Srvice Department Deputy Head, Yem Special Woreda Education Department Head and Deputy Head, primary school teachers, secondary school director and community elders. Besides, a total of 32 married women were purposively selected and consulted using a structured interview guideline, based on the researchers' assumption that they are the most appropriate units of analysis as far as HTPs are concerned.

Methods of Data Analysis and Interpretation: the data which gathered from purposively selected respondents through methods of in-depth interviews/KKIs, FGDs were coded and classified according to common attributes. 
Next, the data in Amharic were translated in to English. The thematically organized FGD and KII/in-depth interview were interpreted and analyzed thematically and descriptively. On the other hand, the structured interview data were entered and analyzed SPSS version 23.0. Basically, frequency distribution and percentages have been used to present data obtained from purposively selected interviewees.

\section{Theoretical Framework and Literature Review}

Harmful Traditional Practices: Literature shows that HTPs are a form of discrimination; they violate the human rights of affected individuals, particularly women and girls. They arise from gender inequality and discriminatory values, which lead to unequal power relations in communities and societies and to violence against women and girls. HTPs include forced or early marriage, so-called 'honor'-based violence and female genital mutilation or cutting (FGM). Harmful traditional practices should be defined as widely as possible and include FGM/C, early and forced marriage, crimes committed in the name of honor, dowry-related violence, and son preference (Action-Aid-UK, nd). These practices which have remote and mysterious origins, and are based on absurd and vague reasons, amount to violence against women and they have proved difficult to eliminate (Kouyate, 2009). Tradition represents the sum total of all behaviors that are learned, shared by a group of people and transmitted from generation to generation. It includes language, religion, types of food eaten, and methods of their preparation, childrearing practices and all other values that hold people together and give them a sense of identity and distinguish them from other groups (ibid).

Child/Early Marriage: Child marriage refers to engagement of a girl to sort of marital arrangement, usually before the age of 18. Consequences of early/forced marriages include: domestic violence and rape; undesired pregnancies; illegal termination of pregnancies; inadequate or even lack of pregnancy follow-up and antenatal care leading to highly risky delivery, and possibly to the death of the expecting young mother (Kouyate, 2009). Growing evidence from sub-Saharan Africa shows that married girls in the region are at greater risk of HIV infection than sexually active, unmarried girls. One study from Johns Hopkins University found higher HIV rates among married women in rural Uganda (18 percent) than young unmarried women (15 percent).5 A study in Kenya and Zambia by University of Chicago researchers found that among 15- to 19-year-old girls who are sexually active, being married increased their chances of having HIV by more than 75 percent.6 These studies investigated a limited number of girls in a select number of countries (UNPF, 2003).

Early marriage harms girls by denying them their childhood and forcing them into marriage (as children they are unable to make a free and informed choice about a future spouse). The practice also denies girls the right to education and health, as early marriage leads to early childbirth for which girls are mentally and physically unprepared. Due to widespread poverty, child marriage also leads to "selling" of girls, particularly to much older men, who can pay impoverished families for a young girl's marriage (Human Rights Commission-Geneva, 2010).

Female Genital Mutilation: The term FGM describes a variety of procedures involving the partial or complete removal of the external female genitalia and/or injury to the female genital organs for cultural, traditional, or other non-therapeutic reasons. 18 More than 130 million girls and women have undergone the procedure, and an estimated two million girls are at risk of FGM every year. FGM is associated with a range of serious health problems, including infection, chronic pain, sexual dysfunction, and obstetric complications. Less is known about the psychological and emotional consequences of FGM, but stress, anxiety, and depression may be associated with the procedure (PATH, 2002).

Female Genital Mutilation (FGM) comprises all procedures that involve partial or total removal of the external female genitalia, or other injury to the female genital organs for non medical reasons. There are broadly four types: Type 1: Partial or total removal of the clitoris and or the prepuce (clitoridectomy), Type 2: Partial or total removal of the clitoris and the labia minora, with or without excision of the labia-majora (excision), Type 3 : Narrowing of the vaginal opening and creating a seal by cutting and placing together of the labia minora and/ or the labia majora, with or without excision of the clitoris (infibulations), and Type 4: All other harmful procedures to the female genitalia for non-medical purposes, for example pricking, piercing, incision, or scraping and cauterization (Women and Girls' Network, 2016). FGM has immediate and legacy psychological impacts on girls and women. These include: fear, shock, betrayal of being subjected to the trauma by loving parents, extended family and friends, anger, sadness, confusion, chronic pain syndrome, anxiety, depression, traumatic memories, flashbacks, nightmares, sleep disorders, anger/ irritability, low self esteem, attachment issues and lack of trust, ambivalence towards family and community, and feeling of incompleteness (Arneson, 2011).

Polygamy: According to literatures in the area, Polygamy involves having two or more spouse at the same time. The most common form is polygyny, where a man can have many wives. Less common, but found in some societies such as Tibet, is polyandry, where a woman can have many husbands. Polygyny was accepted or even preferred in three/fourths of preindustrial traditional societies, though it was seldom practiced by the commoners or lower classes. It tended to occur most frequently in societies where the route to winning wealth and political power was through attracting followers or having lots of sons to hunt for the family head or defend the family's 
land (Coontz, 2006).

\section{Results and Discussion}

Socio-demographic Composition of Interviewees: As it has been described in the 'methods' part, a total of 32 married women were purposively selected based on the researchers' assumption that they are the most appropriate units of analysis as far as HTPs are concerned. The following table contains information about some socio-demographic characteristics of the study participants in the interview.

Table 1: Socio-demographic Composition of Interviewees

\begin{tabular}{|c|c|c|c|}
\hline \multicolumn{2}{|c|}{ Characteristic/variable } & \multirow{2}{*}{$\begin{array}{l}\text { Frequency } \\
0\end{array}$} & \multirow{2}{*}{ Percentage } \\
\hline Sex & Male & & \\
\hline & Female & 32 & 100 \\
\hline & Total & 32 & 100 \\
\hline \multirow[t]{6}{*}{ Age } & $14-23$ & 9 & 32 \\
\hline & $24-33$ & 11 & 34.38 \\
\hline & $34-43$ & 5 & 15.63 \\
\hline & $44-53$ & 6 & 18.75 \\
\hline & 54 and above & 1 & 3.13 \\
\hline & Total & 32 & 100 \\
\hline \multirow[t]{4}{*}{ Marital Status } & Single & 0 & 0 \\
\hline & Married & 29 & 90.63 \\
\hline & Divorced/widowed/separated & 3 & 9.37 \\
\hline & Total & 32 & 100 \\
\hline \multirow[t]{4}{*}{ Location } & Toba cluster & 10 & 31.25 \\
\hline & Tigir cluster & 9 & 28.13 \\
\hline & Fofa Cluster & 13 & 40.63 \\
\hline & Total & 32 & 100 \\
\hline \multirow[t]{3}{*}{ Religious Affiliation } & Muslim & 10 & 31.25 \\
\hline & Christian & 22 & 68.75 \\
\hline & Total & 32 & 100 \\
\hline \multirow[t]{5}{*}{ Educational Status } & Illiterate (Did not attended school at all) & 11 & 34.37 \\
\hline & Primary school $(1-8)$ & 17 & 58.13 \\
\hline & Secondary school (9-12) & 4 & 12.5 \\
\hline & $\begin{array}{l}\text { Beyond secondary school (certificates, diploma, } \\
\text { degree and above) }\end{array}$ & 0 & 0 \\
\hline & Total & 32 & 100 \\
\hline \multirow[t]{5}{*}{ Occupation } & House wife & 18 & 56.25 \\
\hline & Trade (small business activities) & 5 & 15.63 \\
\hline & Trade and farming & 7 & 21.88 \\
\hline & Farming (as a woman headed family) & 2 & 6.25 \\
\hline & Total & 32 & 100 \\
\hline \multirow[t]{6}{*}{ Family Size } & $1-3$ & 7 & 21.88 \\
\hline & $4-6$ & 16 & 50 \\
\hline & $7-9$ & 7 & 21.88 \\
\hline & $10-12$ & 2 & 6.25 \\
\hline & 13 and above & 0 & 0 \\
\hline & Total & 32 & 100 \\
\hline
\end{tabular}

Source: Own study/survey: 2019

As it has already been expressed in the previous sections, all the interview participants are women who are married or had marriage experience. In relation to this, the majority, $(90.63 \%)$ of the respondents are still living a married life. In terms of the age composition of the interviewees, a fairly majority (34.38\%) fall under 24-33 age category. The next majority related to age composition accounts about 32\%, which is between 14 and 23 age category.

As far as the distribution of interviewees based on specific location within Yem Special Woreda is concerned, $40.63 \%, 31.25 \%$ and the remaining $28.13 \%$ belong to Fofa, Toba and Tigir administrative clusters respectively. In terms of religious affiliation, the majority of the respondents are Christians, which is $68.75 \%$ and $31.25 \%$ are Muslims. As far as educational status is concerned, $58.13 \%$ of the respondents had primary schooling, while the next highest $34.37 \%$ were found to have no any kind of formal education. $56.25 \%$ of the study participants are housewife in terms of occupation. $50 \%$ of the respondents reported to have a family 
size/member between 4 and 6 .

Parental Experience and Age Category of the Youngest Child

Table 2: Parental Experience and Age of the Youngest Child

\begin{tabular}{|c|c|c|c|}
\hline \multicolumn{2}{|l|}{ Question/variable } & Frequency & Percentage \\
\hline \multirow{3}{*}{$\begin{array}{l}\text { Do you have a biological or adopted } \\
\text { child? }\end{array}$} & Yes & 27 & 84.37 \\
\hline & No & 5 & 15.63 \\
\hline & Total & 32 & 100 \\
\hline \multirow[t]{7}{*}{ How old is your youngest child? } & Have no child & 5 & 15.63 \\
\hline & $<5$ & 19 & 59.38 \\
\hline & $6-10$ & 4 & 12.5 \\
\hline & $11-15$ & 3 & 9.38 \\
\hline & $16-20$ & 1 & 3.13 \\
\hline & $>20$ & 0 & 0 \\
\hline & Total & 32 & 100 \\
\hline
\end{tabular}

Source: Own study/survey 2019

As it can be simply inferred from the table above, $87.37 \%$ of the interviewees have child. The remaining $15.63 \%$ did not report to have child at all. This could be either due to the fact that the couples did not have biological/adopted child yet or lost their child because of different causalities. Majority the interviewees $(59.38 \%)$ responded that their youngest child is under the age of 5. The above two questions were basically aimed at addressing HTPs that are performed on children together with an objective to assess the issue in the more recent time. It is assumed by the researchers that the best information about HTPs could be given by married mothers, particularly those with child/children.

Harmful Traditional Practices in the Study Area Table 3: Prevalence of HTPs and Experience of Study Participants Relating to the Practices

\begin{tabular}{lll}
\hline HTPs Experience & Frequency & Percentage \\
\hline Early Marriage & 4 & 12.5 \\
FGM/C (Regarding both the mother and child/girl) & 0 & 0 \\
Marriage by Abduction & 2 & 6.25 \\
Polygamy & 5 & 15.63 \\
Drinking Kosso during pregnancy & 3 & 9.38 \\
Abdominal Massage with butter (during birth giving) & 6 & 18.75 \\
Encouraging excessive fertility & 8 & 25 \\
Feeding butter to new born babies & 13 & 40.63 \\
Ovulectomy (on children) & 7 & 21.88 \\
No experience of HTPs & 1 & 3.13 \\
Total & $49^{*}$ & 100 \\
\hline
\end{tabular}

Source: Own study/survey 2019

Early/Child Marriage: As the data contained in table no. 3 shows, $12.5 \%$ of the study participants reported to have experienced early/child marriage. Off course, as compared to feeding children with butter $(40.63 \%)$ and encouragement of excessive fertility (25\%), child marriage as a harmful practice is not prevalent one. Additionally, the data may not directly demonstrate the current status of child marriage since the study participants were asked to report their past experiences. This could lead us to infer that this particular practice is not among the most prevalent HTPs.

A health extension worker at Azezata Kebele, in an in-depth interview explained the situation about child marriage as follows.

...Child marriage has also shown dramatic decline in Yem Special Woreda. This is due to the governments', particularly law enforcement bodies' strong commitment in criminalizing the practice and prosecuting offenders. However, in this and the past year, HTPs like home delivery and child marriage are showing some symptoms of revival. This is due to governments administrative gaps related to the nationwide transition process. That is what I think.

Also, FG discussions also show local communities are bringing attitudinal and behavioral changes with regard to improving the age-at-marriage of girls. Girls are being encouraged more for schooling than engaging in marital relationships. Another key informant added the following information regarding the encouraging changes that are witnessed in relation to avoiding child marriage.

...Previously, girls were pressurized to get married at their youngest ages. The reasons for such a practice were stereotypes, poor economic status of girl's parents, family pressures/desire, and immature prior agreement of the couples. However, nowadays, our 
girls are sent to schools, not obliged to be married. We, the community elders are committed to educating the community to totally abandon HTPs in general and child marriage in particular based on the information we get from government and health extension workers.

While the more localized aspect of child/early marriage seems to be improving, in the more urbanizing part of Yem Special Woreda (Saja town), the practice is worsening as per the information obtained from Women and Children Affairs Department in the study area. Based on the reports and discussions made with study participants, very young girls are engaging in marital relationships with usually older men. Some girls both from the rural areas and Saja town are simply deceived by men for simple gifts, materials and money. Various reasons are given to child/child marriage. Ensuring virginity, increasing fertility potential, to get early access to material benefits, conforming to social norms and others are among the main justifications given to child marriage.

Female Genital Mutilation/Cutting: Based on the responses of study participants none of them reported to have experienced FGM/C both on themselves and their female child. In the FGDs and key-informant interviews, it was repeatedly expressed that this type of HTPs is very uncommon among the Yem people and it is a culturally discouraged and unknown thing. In a key-informant interview with Yem Special woreda Women and Children Affairs Office Head, the following has been highlighted concerning FGM/C in the study area.

...Female genital mutilation is not common in our area. It is not practiced since the past times and local communities are not practicing it. However, in the most recent time, there is a potential for the practice to penetrate in to our Special woreda, especially in kebeles that share administrative borders with Oromia region and Hadiya Zone.

Generally, the survey, FGDs and interviews showed that FGM is not a serious problem to worry about in Yem Special Woreda. But still, there is a strong need to work with neighboring borders since the practice has a potential to get practiced through social interactions.

Feeding Butter to New Born Babies: As the data contained in the above (table no. 03) shows, $40.63 \%$ of the interviewees answered that they use fresh butter to feeding their babies. The local justifications to this practice include: for energy, strength and growth, as a customary practice transmitted from generation to generation (culturally supported), as food for the new born, for steady and healthy growth, and as replacement for breast milk (when the baby is not able to use breastfeed because of illness or other reasons). HEWs who have involved in the study seriously reported that there are still some mothers doing such practice before babies reach 6 months age, emphasizing that this thing is dangerous to the health of children.

Marriage by Abduction: 6.25\% of participants in the study answered that they have established marital relationship by abduction. However, assuming that this may not tell the current status of this harmful practice, the researchers tried to triangulate data using FGDs and KIIs. The qualitative data showed that this particular practice has shown significant decrement. However violence against women and girls is also sometimes happening in the study area. The following is a direct quote taken from a police officer at Tigir administrative cluster.

There are around 2500 people and 555 households in this kebele. Violence against women and girls is a worrisome issue. From instance from the period 2010 E.C to 2011 E.C., three cases of rape happened. Girls are raped while returning home from school. Many young boys are out of their parents' guidance. There is also some kind of child neglect. Some children are seen to move here and there the whole day without any purpose.

Polygamy: This type of HTPs is noticed sometimes in the area. Those who are engaged in this type of marital arrangement provide a number of reasons. Husbands see it as a prestigious thing. They also use it as a mechanism of transferring accumulated wealth to number of children and grand children. These people want to have number of children as much as possible. In the most recent time, some men are seen to engage in polygamous marriage because they are losing the close companion and support of their elder children due to education and trading activities in distant urban centers. Polygamous marriage is discouraged by Christian religious leaders, while community leaders tolerate the practice. Also, in the survey $15.63 \%$ of the study participants in the structured interview reported to have practiced polygamy.

Other HTPs Forms: Ovulectomy (Entil masqoret): According to information gained from FGDs and KIIs, this practice happens sometimes in the community. It is performed very traditionally with unclean materials made of woods like bamboo tree. It is applied on children below one year age. It is performed by traditional healers thinking that the child would suffer from tonsillitis otherwise. After cutting the child's ovule, butter is used as a treatment to the wound. The problem is that sometimes the butter might be unhygienic.

Dowry and Excessive Feasting: Excessive amount of money given in the form of dowry to the family of bride is also sometimes witnessed in our locality. In most cases, up to 12,000 birr is given. Even if the money is mostly used for fulfilling home materials and/or equipments for the newly formed family, it causes economic crisis to the groom and his family. In some cases, a farming Oxen is sold for such purposes. This in turn makes families of the groom unable to undertake farming activities. One key informant from Yem Special Woreda Culture and 
Tourism Department clarified the issue as follows.

During marital ceremonies, there is excessive feasting that do not consider the economic status of event organizers. Such extravagant expenditure of resources is also manifested at religious death memorials like Tezikar. Related with death funeral ceremonies, community members also spend a number of days quitting farming and other livelihood activities. The amount of money spent to buy arequi-local liquor for funeral ceremony attendants is also unnecessary expense that harms the economic and social standing of the local community.

Local Justifications Given for Different Types of HTPs: The following table summarizes the locally contextualized justifications given for some types of Harmful practices in the study area. The data were collected using structured interview schedule/guideline, which were post coded according to patterns.

Table 4: Reasons Given for Different Types of HTPs

\begin{tabular}{|c|c|c|}
\hline S/No. & HTPs Type & Justification of Study Participants/Interviewees \\
\hline 1 & Feeding butter to a child & $\begin{array}{l}\text { For energy, strength and growth; } \\
\text { Because it is customary practice transmitted from generation to } \\
\text { generation (culturally supported); } \\
\text { Serve as food; } \\
\text { For steady and healthy growth; and } \\
\text { When the baby is not able to use breastfeed }\end{array}$ \\
\hline 2 & $\begin{array}{l}\text { Massaging the abdomen of a } \\
\text { pregnant women with butter }\end{array}$ & Easing labor/birth giving/delivery \\
\hline 3 & Early marriage & $\begin{array}{l}\text { Because we love each other. } \\
\text { Family order/desire } \\
\text { Meager/deteriorated economic status of parents }\end{array}$ \\
\hline 4 & Polygamous marriage & $\begin{array}{l}\text { It is supported by religion; } \\
\text { The husband wanted to have another additional wife } \\
\text { Seasonal/temporary separation/departure of husband for the sake of } \\
\text { income generation/work. }\end{array}$ \\
\hline 5 & Marriage by abduction & $\begin{array}{l}\text { Because it is not always dangerous. Even if I am married by } \\
\text { abduction, I did not suffer from lasting problems. }\end{array}$ \\
\hline 6 & Home delivery & $\begin{array}{l}\text { Shyness to modern delivery } \\
\text { Transportation and preparation problems } \\
\text { Attitudinal problems }\end{array}$ \\
\hline 7 & Ovulectomy & $\begin{array}{l}\text { To avoid frequent infection of the ovule } \\
\text { It is just a customary practice (It has been done by our } \\
\text { parents/grandparents) }\end{array}$ \\
\hline 8 & FGM & FGM is not supported in Yem (it is not just culturally supported ) \\
\hline
\end{tabular}

Source: Own survey/study 2019

\section{Conclusion and Recommendations}

Conclusion: The data and discussions showed that HTPs that affect children, particularly 'feeding butter to babies' are found to be more prevalent as compared to other forms. This practice could have a number of health related impacts on babies. HTPs such as child/early marriage are nowadays becoming less prevalent as compared to the past times based our data and discussions implications. However, this particular harmful practice is gaining changes in its form and mode of operation, since very young girls are sometimes engaging in sexual and marital relationships with usually older men.

A type of harmful practice that significantly affects girls/women in other parts of Ethiopia, is not a serious problem in Yem Special Woreda. The practice is uncommon in Yem culture as the study shows. However, cross-cultural relations with neighboring cultural communities may still leave a gap where FGM/C get chance to spread to parts of the study area. Similarity, marriage by abduction is not common in the study area based on our systematic investigation. Still occasional acts of rape and other forms of violence against school girls are being witnessed. Polygamous marital arrangements are to some extent prevailing in the study area, especially, in more remote rural kebeles. This practice is done for reasons of prestige, as a mechanism of wealth transferring to more off-springs/children. Polygamy is also performed by elder men who are left support less because their elder children move to other places in search of job opportunities. Other types of HTPs such as dowry, excessive feasting and ovulectomy also prevail in the area.

Recommendations: As it is known, this assessment was initiated to serve as stepping stone for any HTPs related planning, project or intervention. Keeping this point in mind, the following recommendations are forwarded.

* Awareness creation programs: It is highly advisable to dwell on awareness creation programs through community radios, school mini-media, school clubs, in social institutions of Iddir and Iqub, religious 
places and so on.

* Working through HEWs: Health extension workers are playing important role in tackling HTPs against children. However, a more strengthened effort is recommended in this manner to avoid the harmful practices once and for all. 'Tackling HTPs' shall be re-included in the 'eighteen health packages'.

* Strengthening Law Enforcement: The law is an important deterrent tool to unintended and harmful acts. But, for this purpose of law to be materialized, law enforcement against HTPs such as child marriage and violence should be strong enough.

\section{References}

1. Actionaid UK-Gender and Development Network-womankind International Planned Parenthood Federation-Orchid Project (-----------) Harmful Traditional Practices Affecting Women and Girls. Retrieved June 22, 2017

2. ActionAid UK-Gender and Development Network-womankind International Planned Parenthood Federation-Orchid Project (nd). Harmful Traditional Practices Affecting Women and Girls.

3. Arnsen, M. (2011). Female Genital Mutilation: Policies to Encourage Abandonment. Political Science Senior Thesis. Bemidji State University.

4. Assefa,D., Wassie, E.,Getahun, M., Berhaneselassie, M. and Melaku, A. (2005) Harmful Traditional Practices in Ethiopia. Module guide for the Ethiopian Health Center team, Produced in collaboration with the Ethiopia Public Health Training Initiative, The Carter Center, the Ethiopia Ministry of Health, and the Ethiopia Ministry of Education.

5. Boyden, J., Pankhurst, A. and Tafere, T. (2012) Harmful Traditional Practices and Child Protection: Contested Understandings and Customs of Female Early Marriage and Genital Cutting in Ethiopia.

6. Coontz, S (2006). Polygamy: A Historical Background, A Fact Sheet Prepared for the Council on Contemporary Families.

7. Gender and Development Network (---------) Harmful Traditional Practices: Your Questions, Our Answers

8. Human Rights, United Nations Assistance Mission and Office of the UN High Commissioner for Human Rights. (2010). Harmful Traditional Practices and Implementation of the Law on Elimination of Violence against Women in Afghanistan

9. Kouyate, M. (2009). Harmful Traditional Practices Against Women and Legislation: Expert Paper

10. Lemma, NT and Mandefro, FT (2019). Hebo: New Year Ritual of Yem People in South West Ethiopia. International Journal of Multicultural and Multireligious Understanding, 6(4): 588-608.

11. Makundi, L.W. (2009) Harmful cultural practices as violations of girls' human rights: female genital mutilation in Tanzania and South Africa.

12. Milkyas L (2017). Ethno-History of Yem People. Southern Nations, Nationalities and Peoples Regional State Bureau of Culture and Tourism.

13. PATH. (2002). Violence against Women: Effects on Reproductive Health.

14. UNICEF Ethiopia (2015) Harmful Traditional Practices: Briefing Note.

15. United Nations Population Fund (2003). Obstetric Fistula Needs Assessment Report: Findings from Nine African Countries.

16. Women and Girls Network (2016). Hidden Scars: Understanding the Trauma and Psychological Impact of Harmful Practices. Good Practices Briefing, London. 